Editorial

\title{
New Horizons in Robotic Surgery: DaVinci Begins to Compete
}

\section{Nuevos horizontes en cirugía robótica: DaVinci comienza a competir}

\author{
Rafael Andrés Clavijo Rodríguez ${ }^{1,2}$ René Javier Sotelo Noguera ${ }^{3}$ \\ ${ }^{1}$ Fundación Universitaria de Ciencias de La Salud, Bogotá, Colombia \\ ${ }^{2}$ Department of Urology, Hospital Infantil Universitario de San José, \\ Bogotá, Colombia \\ ${ }^{3}$ Institute of Urology, University of Southern California, Keck School \\ of Medicine, Los Angeles, California, United States \\ Urol Colomb 2021;30(3):e153-e154.
}

The use of robotic technology in minimally invasive surgery has expanded worldwide in the last two decades. Currently being the DaVinci system of the Intuitive Surgical company, one of the most used in many surgical specialties within them, Urology.

This system has obtained more than 1500 patents in the robotics area; however, some have already expired. Thus, allowing the development of new platforms as an alternative to the monopoly achieved by this system.

Some robotic platforms in actual development feature a modular design, open console, smaller instruments $(<8 \mathrm{~mm})$, and haptic feedback (tactile sensation). These new designs of robotic surgery technology highlight cost-effective systems, single port surgery, artificial intelligence for machine learning, but it should be noted that they face a long and complex process of clinical studies and approval by regulatory entities. ${ }^{1}$

The SENHANCE surgical system, approved by the Food and Drug Administration (FDA) since 2017, and the Korean robotic system REVO-I, also approved in 2017 for local usage, have been Intuitive Surgical's competitors and had set the beginning for other robotic surgery companies to be available at the market. With both systems, multiple abdominal procedures have been performed in general surgery, urology, and gynecology. The existing medical literature to date shows that they are reliable instruments, with good results in terms of safety, in addition to oncological or functional follow-up according to the pathology; comparable results with those obtained with the DaVinci system were demonstrated. ${ }^{2-4}$

Other robotic systems worth mentioning are the "German Robot" AVATERA and the Japanese Medicaroid robot HINOTORI. This last one with a mission that enhances Asimov's laws of robotics "to serve and help humans, not replace humans." The HINOTORI obtained its license for usage in 2020 by that country, but it still does not have preclinical studies or clinical data in humans, still in the development stage.

It must be highlighted what two medical device companies have done as they launched robotic surgery facilities at different latitudes of the world, each in their way, globalizing their market and starting the real competition for Intuitive. Those are Versius Surgical Robotic System - CMR Surgical in the UK with installations in India, Australia, and their own country. The other is Medtronic, recognized as one of the giants in medical devices in the world; its robotic surgical system, HUGO, has systems already installed in Latin America, Panama, and Chile with surgical programs that successfully took off a few months ago at lower costs. ${ }^{5-7}$

There is a great expectation with the project created with the merge of two large companies, Johnson \& Johnson and Google, VERB SURGICAL, several years working on their robotic system. However, they have not yet come to light with their device; It has been an airtight organization in terms of system development details, but this system is expected to compete with high-quality standards.

Robotic-assisted surgery is here to stay. A significant limitation for its expansion has mainly been its high acquisition, maintenance, and operation costs. However, these new platforms are intended to be more accessible to all health systems worldwide so they can gain from the advantage of the well-known benefits of minimally invasive surgery. Worldwide, 6,335 units of the DaVinci system $^{8}$ have been installed. Thus, reiterating this system's reliability and exponential growth; even more, the search of using new technologies. DaVinci begins to compete with rivals of excellent quality and potential, leaving its previous monopoly to enter an era of new challenges to continue in the "game."
Address for correspondence Rafael Andrés Clavijo Rodríguez, MD, Fundación Universitaria de Ciencias de la Salud, Hospital Infantil Universitario de San José, Bogotá, Colombia (e-mail: rafaclavijo@gmail.com).
DOI https://doi.org/ 10.1055/s-0041-1737013. ISSN 0120-789X. e ISSN 2027-0119.
(C) 2021. Sociedad Colombiana de Urología. All rights reserved. This is an open access article published by Thieme under the terms of the Creative Commons Attribution-NonDerivative-NonCommercial-License, permitting copying and reproduction so long as the original work is given appropriate credit. Contents may not be used for commercial purposes, or adapted, remixed, transformed or built upon. (https://creativecommons.org/ licenses/by-nc-nd/4.0/)

Thieme Revinter Publicações Ltda., Rua do Matoso 170, Rio de Janeiro, RJ, CEP 20270-135, Brazil 
The market for surgical robots surpassed USD 4.6 billion in 2020. It is projected to grow at a compound annual rate of over 17.4\% between 2021 and 2027. The increasing prevalence of chronic diseases and the increasing number of surgical procedures worldwide will create lucrative growth opportunities for these systems. ${ }^{9}$ Technological advances concerning its applications, functionality, and precision will influence the expansion of the market. Similarly, increased health outgoing in developing countries will result in more growth opportunities that will increase the acquisition of these new robotic assistive technologies.

Urologists have been continuously at the forefront of new medical devices and surgical technologies; it will be part of our responsibility to become familiar with the new robotic surgical systems as they become commercially available.

\section{References}

1 Rassweiler JJ, Autorino R, Klein J, et al. Future of robotic surgery in urology. BJU Int 2017;120(06):822-841
2 Samalavicius NE, Janusonis V, Siaulys R, et al. Robotic surgery using Senhance ${ }^{\circledR}$ robotic platform: single center experience with first 100 cases. J Robot Surg 2020;14(02):371-376

3 Kim DK, Park DW, Rha KH. Robot-assisted partial nephrectomy with the REVO-I Robot Platform in porcine models. Eur Urol 2016; 69(03):541-542

4 Chang KD, Abdel Raheem A, Choi YD, Chung BH, Rha KH. Retziussparing robot-assisted radical prostatectomy using the Revo-i robotic surgical system: surgical technique and results of the first human trial. BJU Int 2018;122(03):441-448

5 Thomas BC, Slack M, Hussain M, et al. Preclinical evaluation of the versius surgical system, a new robot-assisted surgical device for use in minimal access renal and prostate surgery. Eur Urol Focus 2021;7(02):444-452

6 Kaouk JH, Bertolo R. Single-site robotic platform in clinical practice: first cases in the USA. Minerva Urol Nefrol 2019;71 (03):294-298

7 Seeliger B, Diana M, Ruurda JP, Konstantinidis KM, Marescaux J, Swanström LL. Enabling single-site laparoscopy: the SPORT platform. Surg Endosc 2019;33(11):3696-3703

8 https://isrg.intuitive.com/node/18356/pdf

9 https://www.gminsights.com/industry-analysis/\%20surgicalrobots-market 